\title{
Gill worm Ancyrocephalus percae (Ergens 1966) outbreak negatively impacts the Eurasian perch Perca fluviatilis $L$. stock of Lake Constance, Germany
}

\author{
J Behrmann-Godel ${ }^{1}$, S Roch ${ }^{1}$ and A Brinker ${ }^{2}$ \\ 1 Limnological Institute, University of Konstanz, Konstanz, Germany \\ 2 Fisheries Research Station Baden-Württemberg, Langenargen, Germany
}

Keywords: Dactylogyridae.epizootic disease, Monogenea, perch.

The monogenean gill parasites of the genus Ancyrocephalus (Creplin 1839; Ancyrocephalidae, Dactylogyridae) are monoxenous parasites of freshwater fish (Ergens 1966; Šimková et al. 2003; Šimková, Matejusová \& Cunningham 2006). Adult trematodes locate mainly on the gills of the host, where they produce eggs that are released into the aquatic environment. The eggs hatch into free-living, ciliated oncomiracidia, which seek a host and migrate as post-oncomiracidia to the gills, where they grow to adulthood (Chubb 1977; Cone \& Burt 1981). Two species have been found infecting Eurasian perch, Perca fluviatilis L.: A. paradoxus and $A$. percae. Whereas $A$. paradoxus is found mainly on pikeperch Sander lucioperca L. and S. volgensis (Gmelin 1789) and only occasionally on Eurasian perch, $A$. percae, seems to be host specific to perch (Ergens 1966; Chubb 1977; Kritscher 1988; Molnár \& Székely 1995; Moravec 2001; Šimková et al. 2003, 2006). Other members of the order Dactylogyridae are well-known causes of fish epizootics, especially under stress conditions such as in crowded aquaculture facilities (Thoney \& Hargis 1991). However, to the authors' knowledge, there have been no reports so far concerning epizootic

Correspondence J Behrmann-Godel, Limnological Institute, University of Konstanz, Mainaustrasse 252. 78457 Konstanz, Germany (e-mail: Jasminca.Behrmann@uni-konstanz.de) outbreaks of Ancyrocephalus sp. targeting Eurasian perch in wild or cultured fish populations.

In Lake Constance, perch are the second most important species next only to whitefish in commercial significance. Routine surveys on perch cohort strength, growth and health have been conducted regularly over several decades on behalf of the lake fishery commission (Internationale Bevollmächtigen Konferenz für Bodenseefischerei; www.ibkf.org), and these include assessments of parasite infection status. Three previous studies have investigated the parasite communities of various fish species in Lake Constance, including pikeperch and perch (Zandt 1924; Özcelik \& Deufel 1989; Balling 1992). The authors conducted a parasite survey of perch in 2008, in which 255 adult perch from 10 sampling locations covering the whole lake area were investigated between March and December (data unpublished). No cases of Ancyrocephalus sp. infection were reported in any of these previous studies, strongly suggesting the parasites were absent from Lake Constance until recently. In the 2 years before this study, fishermen began to report abnormal lesions on perch caught in the lake. On closer inspection, in some fish, the isthmus was found to have been torn away from the lower jaw. During a routine parasite survey in spring 2012, the authors were able to confirm these observations and identified infection with a member of the genus Ancyrocephalus as the cause. Recognizing this as a new parasite in the locality, the current study set out to identify the species and assess the 
infection status of perch in Lake Constance, by analysing the parasite burden of different age classes sampled at various locations during spring, summer and autumn of 2012. Additionally, we consider possible negative impacts of Ancyrocephalus on the health of Lake Constance perch, showing a correlation between intense infections and lesions in perch gill isthmus.

A total of 539 perch from three age classes, young of the year $(0+), 1$ year old $(1+)$ and adults (ad), were sampled in Upper Lake Constance (Table 1). Fish were killed by a blow to the head and transported to the laboratory on ice. Upon arrival, fish were individually transferred to small plastic bags containing $2-5 \mathrm{~mL} 0.64 \% \mathrm{NaCl}$ solution and kept on ice until dissection (within max. of 4 days). In some adult fish, heads were cut off and frozen individually at $-80{ }^{\circ} \mathrm{C}$ in small plastic bags containing brine, as described above. In a preliminary test, we verified that neither the storage on ice for up to 4 days in $\mathrm{NaCl}$ solution nor the freezing and thawing of fish heads has led to any loss of information. Several Ancyrocephalus on dead fish stored in cold condition were found to be still alive and moving after 4 days. Furthermore, dead Ancyrocephalus on fish stored in $\mathrm{NaCl}$ solution for 4 days at $4^{\circ} \mathrm{C}$, were well preserved and could be identified easily. Comparing Ancyrocephalus counts from fresh hosts and frozen and thawed fish heads confirmed no difference in parasite numbers. The gills and isthmus of every individual were necropsied for Ancyrocephalus. The location and number of trematodes (isthmus or gills) were noted. From perch caught in autumn, microscopic images were taken of every wound at the isthmus. Using these pictures, the length and width of every wound were measured to the nearest $0.5 \mathrm{~mm}$. Worms were identified by morphology, referring to earlier descriptions in the literature (Ergens 1966). To examine the surface structure of Ancyrocephalus from perch, scanning electron microscopy (SEM) pictures were taken. Fifteen parasite individuals fixed in $70 \%$ ethanol were washed in water and mounted on a specimen stub. The stub was placed in an airtight glass vial containing an acetone-saturated cotton wool swab and incubated overnight. After air drying, the parasites were sputter-coated with palladium-gold (Emitech K550) and photographed with a Zeiss DSM960A scanning electron microscope. Five worms were chosen at random from individual perch and stored in 100\% ethanol for genetic analysis. Additionally, six pikeperch Sander lucioperca L. were caught in Lake Constance and examined for Ancyrocephalus infection. Six worms were found infecting the gills, and these specimens were retained for further study: three for morphologic analysis and three for genetic determination. DNA was extracted from individual parasites using the Chelex extraction method (Criscione \& Blouin 2004). Two fragments of the rDNA were amplified using amplification conditions as described in the literature: first, a part of the LSU rRNA gene, using the primers D1 and D2 (Sonnenberg, Nolte \& Tautz 2007) or C1 and D2 (Hassouna, Mithot \& Bachellerie 1984) and the complete ITS1, and second, a part of the $5.8 \mathrm{~s}$ region, using the primers D1 and D2 (Galazzo et al. 2002). PCR products were purified and sequenced at GATC, Germany (sequence accession numbers KF499079-KF49908 $0)$. The sequences obtained were BLASTed against the GenBank database.

Morphological and genetic analyses showed that two different Ancyrocephalus species were infecting

Table 1 Ancyrocephalus percae parasite burden of Lake Constance perch caught at four localities: Egg (EG), Konstanzer Trichter (KT), Langenargen (LA) and Seefelden (SF) in 2012

\begin{tabular}{|c|c|c|c|c|c|c|c|}
\hline Season & Month & LOC & Age (TL) & N host & Prev & Int (max) & \\
\hline \multirow[t]{3}{*}{ Spring } & April/May & EG & Ad (20.7) & 20 & 50 & $15(44)$ & \\
\hline & May & $\mathrm{KT}$ & Ad (20.4) & 20 & 60 & $31(91)$ & \\
\hline & June & LA & Ad (19.7) & 20 & 85 & 53 (136) & \\
\hline \multirow[t]{4}{*}{ Summer } & August & SF & $0+(4.8)$ & 100 & 97 & 32 (120) & \\
\hline & August & $E G$ & $0+(4.9)$ & 97 & 54 & $11(50)$ & \\
\hline & August/September & LA & $0+(6.9)$ & 91 & 53 & na & \\
\hline & August & $E G$ & $1+(10.5)$ & 50 & 72 & 39 (150) & \\
\hline \multirow[t]{3}{*}{ Autumn } & November & EG & Ad (21.1) & 61 & 77 & $18(81)$ & $\mathrm{N}$ \\
\hline & November & EG & $1+(10.2)$ & 39 & 77 & $34(215)$ & \\
\hline & November & $E G$ & $0+(6.7)$ & 41 & 27 & $4(13)$ & $20 \mathrm{~km}$ \\
\hline
\end{tabular}

Shown are fish age $(>1$ year old $=$ Ad, 1 year old $=1+$ and young of the year $=0+)$, fish total length in centimetre $(\mathrm{TL})$, number of hosts investigated $\left(\mathrm{N}_{\text {host }}\right.$ ), prevalence of infection (Prev) in percentage, mean intensity of infection (Int) and maximum number of parasites (max), na $=$ not analysed. 
pikeperch and perch, respectively, in Lake Constance. Parasites from pikeperch showed morphological characteristics (after Ergens 1966) of A. paradoxus (main differentiating characteristics: length of copulatory complex $0.151 \mathrm{~mm}$, length of marginal hooks $0.02 \mathrm{~mm}$, marginal hooks of dactylogyroid type). The GenBank search using the LSU rDNA fragment yielded a $100 \%$ identity match with a published $A$. paradoxus sequence (accession number: AJ969952, Šimková et al. 2006). In contrast, parasites from perch showed morphological characteristics of $A$. percae (length of copulatory complex $0.090 \mathrm{~mm}$, length of marginal hooks $0.002 \mathrm{~mm}$, marginal hooks of embryonal type) although several parasites were much larger (2-4 mm body length) than previously described (1-2 mm after Ergens 1966). The ITS1-5.8s sequence yielded a $100 \%$ identity with a published
A. percae sequence (accession number: AJ490166, Šimková et al. 2003). Comparing sequences of both species revealed 24 and 26 substitutions at LSU rDNA (792 bp fragment length) and ITS1-5.8s (522 bp fragment length), yielding 97\% and $95 \%$ sequence identity, respectively.

Ancyrocephalus percae was found almost exclusively infecting the isthmus of perch close to where it joins the lower jaw (Fig. 1). Only in four fish, a few $A$. percae (1-2) were found attached to the gills. On the isthmus, the parasites were always found in oval wounds, filled with necrotic tissue. There were between one and three such wounds on either side of the isthmus. On average, wounds were $3-6 \mathrm{~mm}$ long and 2-5 mm wide (Fig. 1a), and each might contain numerous aggregated parasites. Those parasites were attached to the inside of the wounds with their posterior hooks, while their anterior ends were
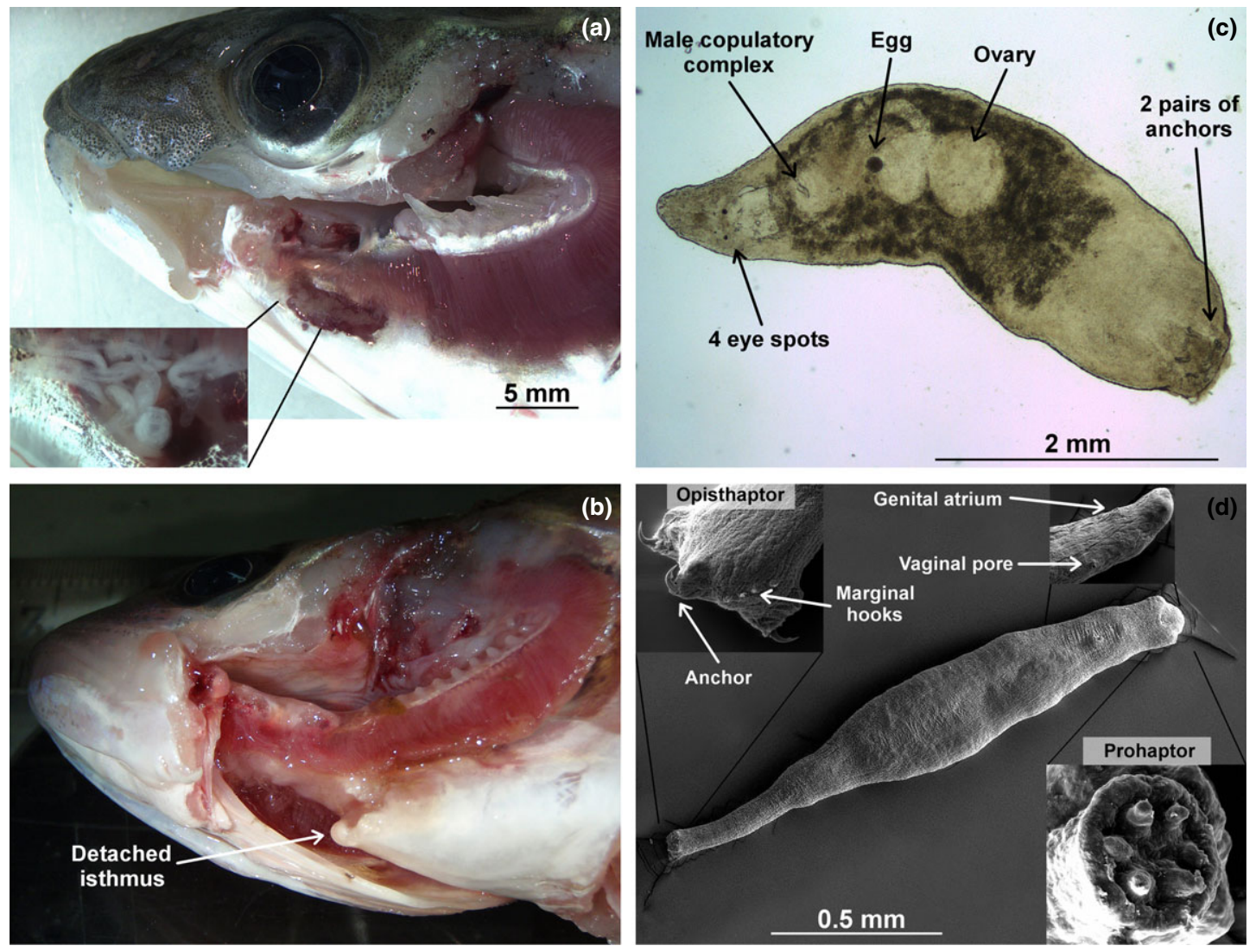

Figure 1 Infection of perch from Lake Constance with the gill worm Ancyrocephalus percae. (a) Aggregation of parasites in a wound at the isthmus. The operculum and distal part of gills have been removed for a better view. (b) Heavily infected fish (isthmus is detached from lower jaw), operculum and parasites removed for better view. (c) Light microscopic view of an adult $A$. percae from perch showing morphological characters. (d) Scanning electron microscopy picture of ventral body of an adult $A$. percae showing morphological characters. 
mostly facing the observer such that the four characteristic eye spots were clearly visible (Fig. 1a). On two adult fish, the tissue connecting the isthmus with the lower jaw was destroyed, causing distal detachment of the isthmus from the lower jaw (Fig. 1b).

Prevalence was between $27 \%$ and $97 \%$ at the different locations investigated (Table 1). Mean intensity of infection varied between 4 and 52 parasites per fish; however, $2 \%$ of fish had 100 parasites or more (max. 215). All three age classes investigated were infected with A.percae. Prevalence was highest in $0+$ perch caught at locality SF in summer, significantly higher than in $0+$ perch from the other two localities sampled at the same time (Fisher's exact test: $S F$ vs. EG, $P<0.001$; SF vs. LA, $P<0.001$; LA vs. EG, $P=1.0$ after Bonferroni correction), indicating variability in the rate of infection between localities. At locality EG, prevalence in $0+$ perch decreased significantly from summer to autumn (Fisher's exact test: $P=0.004$ ) as did intensity of infection (Wilcoxon rank sum test: $P=0.010$; Table 1). However, for the same sampling occasions, prevalence and intensity remained unchanged for $1+$ perch (prevalence: Fisher's exact test: $P=0.50$; intensity: Wilcoxon rank sum test $P=0.385$; Table 1 ). For adults at locality EG, prevalence increased from spring to autumn (Fisher's exact test: $P=0.018$ ), whereas intensity of infection did not change between seasons (Wilcoxon rank sum test: $P=0.496$; Table 1 ).

The high parasite densities in wounds at the isthmus of Lake Constance perch appear to fit the description of lesions reported by fishermen in the preceding years. Fish with several grades of tissue necrosis were recorded, ranging from slight destruction to complete detachment of the isthmus from the lower jaw (Fig. 1b). Although we did not find direct evidence of parasite-induced host mortality, the extraordinarily high prevalence and intensity of infection found could be the first signs. The decrease in parasite prevalence and intensity of $0+$ perch from August to November may be indicative of increased mortality in the youngest age class. No such decrease was seen in older fish sampled at the same time (Table 1). However, an alternative explanation for a decrease in parasite infection in the $0+$ age class could be differences in natural mortality cycles of parasites between age classes of perch. In Lake Constance, the habitats of different perch age classes only partly overlap (Wang \& Eckmann 1994), which may result in variability in abiotic factors such as water temperature. Such differences may influence the natural mortality cycle of the parasite. Followup experiments may show whether differences in natural mortality cycles exist in this specific parasite-host system.

Infection intensity of Lake Constance perch of all age classes with $A$. percae was found to be extraordinarily high at all four localities investigated, compared with that reported for $A$. percae and $A$. paradoxus on perch and pikeperch, respectively (Chubb 1977; Kritscher 1988; Molnár \& Székely 1995; Moravec 2001 but see Starovoitov 1986). This is remarkable considering that the previous parasite survey 2008 recorded no cases of $A$. percae infection on perch. The data strongly indicate an introduction of the parasite into Lake Constance between 2008 and 2012 and a very rapid propagation of parasites within the perch population. We have no secure knowledge on how both Ancyrocephalus species arrived in Lake Constance, but a likely scenario is that the parasites were introduced by accident along with stocked pikeperch. It is a common practice to stock the lake with one summer pike perch raised in natural ponds (IBKF yearly reports, available per request). As $A$. paradoxus infections of pikeperch have been reported for many parts of Europe, including Germany (www. faunaeur.org), an infection of pikeperch fry within these natural ponds may well have occurred. At the same time, perch fry infected with $A$. percae, also occurring in those natural ponds, may have been stocked accidentally into Lake Constance. However, the intensity of infection of perch in Lake Constance and the severity of injury caused are exceptional and have yet to be explained. Commonly, elsewhere, only few Ancyrocephalus sp. appear to infect pikeperch or perch and are mainly found localized at the fish's gills (Molnár \& Székely 1995; Rolbiecki \& Rokicki 1996). No negative impacts from infection with low intensities of both Ancyrocephalus species have been described, although at higher intensities, A. paradoxus may cause pathogenicity by gill tissue destruction close to parasite attachment sites (Molnár \& Székely 1995). Of particular interest in the context of this study is, however, an outbreak of $A$. paradoxus in the Kurish Gulf of the Baltic Sea in 1984 (Starovoitov 1986). Massive infections of pikeperch were recorded, and high percentages of $A$. paradoxus were found at the isthmus of fish. Highest intensities of infection at the isthmus were found in 
$0+$ and $1+$ pikeperch, whereas in older fish, parasites were mainly found infecting the gills. Negative impacts were reported, however, only for the youngest age class of pikeperch investigated, whereas in our study, negative impacts of intensive infections were reported for all age classes of perch investigated.

Lake Constance has undergone a dramatic change in nutrient status within recent decades, due to anthropogenic impact, as a result of which ecological alterations are to be expected (Stich \& Brinker 2010). Several neobiota have invaded the lake, and no fewer than 16 alien species have been recognized since the 1960s (www.neozoen-bodensee.de). In the light of this environmental change, the cumulative effects that multiple stressors have on native species are currently becoming a major concern, and recently, Vidal-Martínez et al. (2010) and Marcogliese \& Pietrock (2011) have discussed their negative effect on immune function and animal health. Following these considerations, we may hypothesize that the accidental introduction of A. percae into Lake Constance has finally resulted in an epizootic outbreak in the immunologically compromised perch host population, which may not have occurred under more stable environmental conditions.

Intensive follow-up laboratory experiments on the impact of $A$. percae infections on perch fry and juveniles are planned in the near future to further investigate this issue.

\section{Acknowledgements}

We thank students Christian Witt, Timo Prosenbauer, Melody Reithmann, Dennis Rosskothen, Lisa Breithut, Emily Fischbach and Elizabeth Ostrowski for help in laboratory work, Viola Burkhardt-Gehbauer for technical assistance in taking SEM pictures and Amy-Jane Beer for English correction and helpful comments on the article. In addition, the comments of two unknown referees greatly improved this article. The project was financially supported by the 'Stiftung für Umwelt und Wohnen' of the University of Konstanz.

\section{References}

Balling T. (1992) Saisonale und standortabhängige Verbreitung von Fischparasiten im Bodensee-Obersee und ihr Einfluß auf den Ernährungszustand der Fische. Dissertation thesis. Eberhard-Karls-Universität Tübingen, Germany.
Chubb J.C. (1977) Seasonal occurrence of helminths in freshwater fishes. Part I. Monogenea. Advanced Parasitology 15, 133-199.

Cone D.K. \& Burt M.D.B. (1981) The invasion route of the gill parasite Urocleidus adspectus Mueller, 1936 (Monogenea: Ancyrocephalinae). Canadian Journal of Zoology 59, 2166-2171.

Criscione C.D. \& Blouin M.S. (2004) Life cycles shape parasite evolution: comparative population genetics of salmon trematodes. Evolution 58, 198-202.

Ergens R. (1966) Revision of the helminthofauna of fishes in Czechoslovakia III Genus Ancyrocephalus (s.l.) Creplin 1839 (Monogenoidea: Dactylogyridae). Folia Parasitologica (Praha) 13, 28-35.

Galazzo E., Dayanandan S., Marcogliese D.J. \& McLaughlin J.D. (2002) Molecular systematics of some North American species of Diplostomum (Digenea) based on rDNA-sequence data comparisons with European congeners. Canadian Journal of Zoology 80, 2207-2217.

Hassouna N., Mithot B. \& Bachellerie J.-P. (1984) The complete nucleotide sequence of mouse 28sRNA gene. Implications for the process of size increase of the large subunit rRNA in higher eukaryotes. Nucleic Acids Research 12, 3563-3583.

Kritscher E. (1988) Die Fische des Neusiedlersees und ihre Parasiten. VII. Trematoda: Monogenea und Zusammenfassung. Annalen des Naturhistorischen Museums in Wien 90, 407-421.

Marcogliese D.J. \& Pietrock M. (2011) Combined effects of parasites and contaminants on animal health: parasites do matter. Trends in Parasitology 27, 123-130.

Molnár K. \& Székely C. (1995) Parasitological survey of some important fish species of Lake Balaton. Parasitologia Hungarica 28, 63-82.

Moravec F. (2001) Checklist of the Metazoan Parasites of Fishes of the Czech Republic and the Slovak Republic (1873-2000). Academia, Praha.

Özcelik A. \& Deufel J. (1989) Investigations on the occurrence of helminth parasites of Lake Constance. Zeitschrift fur Angewandte Zoologie 76, 27-59.

Rolbiecki L. \& Rokicki J. (1996) Parasitic metazoa of pikeperch (Stizostedion lucioperca L.) in the gulf of Gdansk. Crangon - Issues of the Marine Biology Centre in Gdynia 1, $73-85$.

Šimková A., Plaisance L., Matejusová I., Morand S. \& Verneau O. (2003) Phylogenetic relationships of the Dactylogyridae Bychowsky, 1933 (Monogenea: Dactylogyridea): the need for the systematic revision of the Ancyrocephalinae Bychowsky, 1937. Parasitolology 54, $1-11$.

Šimková A., Matejusová I. \& Cunningham C.O. (2006) A molecular phylogeny of the Dactylogyridae sensu Kritsky \& Boeger (1989) (Monogenea) based on the D1-D3 domains of large subunit rDNA. Parasitology 133, 43-53.

Sonnenberg R., Nolte A.W. \& Tautz D. (2007) An evaluation of LSU rDNA D1-D2 sequences for their use in species identification. Frontiers in Zoology 4, 6. 
Starovoitov V.K. (1986) Peculiarities of localization of Ancyrocephalus paradoxus (Monogenea) on the pikeperch Stizostedion lucioperca. Parazitologiia 20, 491-492.

Stich H.B. \& Brinker A. (2010) Oligotrophication outweighs effects of global warming in a large, deep, stratified lake ecosystem. Global Change Biology 16, 877-888.

Thoney D.A. \& Hargis W.J. Jr (1991) Monogenea (platyhelminthes) as hazards for fish in confinement. Annual Review of Fish Diseases 1, 133-153.

Vidal-Martínez V.M., Pech D., Sures B., Purucker S.T. \& Poulin R. (2010) Can parasites really reveal environmental impact? Trends in Parasitology 26, 44.
Wang N. \& Eckmann R. (1994) Distribution of perch (Perca fluviatilis L.) during their first year of life in Lake

Constance. Hydrobiologia 277, 135-143.

Zandt F. (1924) Fischparasiten des Bodensees. Centralblatt fur Bakteriologie 92, 225-269.

Received: 22 March 2013

Revision received: 14 August 2013

Accepted: 15 August 2013 